\title{
Erratum to: Expression of CCR6 on B cells in systemic lupus erythematosus patients
}

\author{
Adrian Y. S. Lee ${ }^{1,2}$ • Jennifer L. Bannan ${ }^{3}$ Murray J. Adams ${ }^{4,5}$ • Heinrich Körner ${ }^{3,6}$
}

Published online: 31 May 2017

(C) International League of Associations for Rheumatology (ILAR) 2017

\section{Erratum to: Clin Rheumatol}

\section{DOI 10.1007/s10067-017-3652-3}

The article was originally published with a missing author. In the recent manuscript, the name of the co-author Murray J. Adams was inadvertently omitted. His name and affiliation have now been added to the author list. The original article was corrected.

Adrian Y. S. Lee and Jennifer L. Bannan contributed equally to this work.

The online version of the original article can be found at http://dx.doi. org/10.1007/s10067-017-3652-3

$\triangle$ Heinrich Körner

Heinrich.Korner@utas.edu.au

1 Western Health, Melbourne, Victoria, Australia

2 School of Medicine, University of Tasmania, Hobart, Tasmania Australia

3 Menzies Institute for Medical Research, University of Tasmania, 17 Liverpool Street, Hobart, Tasmania 7000, Australia

4 School of Health Sciences, University of Tasmania, Launceston, Tasmania, Australia

5 Present address: School of Veterinary and Life Sciences, Murdoch University, Perth, Western Australia, Australia

6 Key Laboratory of Anti-inflammatory and Immunopharmacology, Ministry of Education, Engineering Technology Research Center of Anti-inflammatory and Immunodrugs in Anhui Province, Institute of Clinical Pharmacology, Anhui Medical University, Hefei, Anhui Province, People's Republic of China 